\title{
Case of Multiple Sulfatase Deficiency and Ocular Albinism: A Diagnostic Odyssey
}

\author{
Chitra Prasad, C. Anthony Rupar, Craig Campbell, Melanie Napier, \\ David Ramsay, K.Y. Tay, Sapna Sharan, Asuri N. Prasad
}

\begin{abstract}
Background: Multiple sulfatase deficiency (MSD) is a rare autosomal recessive inborn error of lysosomal metabolism. The clinical phenotypic spectrum encompasses overlapping features of variable severity and is suggestive of individual single sulfatase deficiencies (i.e., metachromatic leukodystrophy, mucopolysaccharidosis, and X-linked ichthyosis). Case Report: We describe a 3-yearold male with severe hypotonia, developmental regression and progressive neurodegeneration, coarse facial features, nystagmus (from ocular albinism), and dysmyelinating motor sensory neuropathy. Ethics approval was obtained from the Western University Ontario. Results: Extensive investigative work-up identified deficiencies of multiple sulfatases: heparan sulfate sulfamidase: $6.5 \mathrm{nmoles} / \mathrm{mg} /$ protein/17 hour (reference 25.0-75.0), iduronate-2-sulfate sulfatase: $9 \mathrm{nmol} / \mathrm{mg} /$ protein/4 hour (reference 31-110), and arylsulfatase A: 3.8 nmoles/hr/mg protein (reference 22-50). The identification of compound heterozygous pathogenic mutations in the SUMF1 gene c.836 C > T (p.A279V) and c.1045C > T (p.R349W) confirmed the diagnosis of MSD. Conclusion: The complex clinical manifestations of MSD and the unrelated coexistence of ocular albinism as in our case can delay diagnosis. Genetic counselling should be provided to all affected families.
\end{abstract}

RÉSUMÉ: Patient atteint d'un déficit multiple en sulfatases et d'albinisme oculaire: odyssée diagnostique. Contexte: Le déficit multiple en sulfatases est une erreur innée du métabolisme. Cette maladie enzymatique rare est transmise de façon autosomique récessive. Le spectre phénotypique clinique inclut des manifestations de sévérité variable qui se chevauchent et il évoque le tableau de déficiences simples en sulfatases (c.-à-d. la leucodystrophie métachromatique, la mucopolysaccharidose et l'ichthyose liée à l'X). Observation clinique: Nous décrivons la présentation clinique d'un garçonnet de 3 ans atteint d'une hypotonie sévère, d'une régression développementale et d'une neurodégénérescence progressive et présentant des traits grossiers du visage, un nystagmus (dû à l'albinisme oculaire) et une neuropathie sensitivo-motrice démyélinisante. Une approbation éthique a été obtenue de la Western University en Ontario. Résultats: Une démarche diagnostique approfondie nous a permis d'identifier des déficits multiples en sulfatases: sulfamidase de l'héparane sulfate: $6,5 \mathrm{nmol} / \mathrm{mg}$ de protéine/17 heures (valeurs de référence 25,0 à 75,0 ), sulfatase de l'iduronate-2-sulfate: $9 \mathrm{nmol} / \mathrm{mg}$ de protéine/4 heures (valeurs de référence 31 à 110) et arylsulfatase A: $3,8 \mathrm{nmol} / \mathrm{heure} / \mathrm{mg}$ de protéine (valeurs de référence 22 à 50). L'identification de deux mutations pathogéniques dans le gène SUMF1 c. $836 \mathrm{C}>\mathrm{T}$ (p.A279V) et c. $1045 \mathrm{C}>\mathrm{T}$ (p.R349W) chez le patient a confirmé le diagnostic de déficit multiple en sulfatases et son statut d'hétérozygote composé. Conclusion: Les manifestations cliniques complexes du déficit multiple en sulfatases et la coexistence non reliée de l'albinisme oculaire, telles que présentes chez notre patient, peuvent retarder le diagnostic. Toutes les familles atteintes de cette maladie devraient bénéficier d'un conseil génétique.

Keywords: Multiple sulfatase deficiency, mucopolysaccharidosis, metachromatic leukodystrophy, developmental regression and ocular albinism

doi:10.1017/cjn.2014.12

Can J Neurol Sci. 2014; 41: 626-631

\section{INTRODUCTION}

Multiple sulfatase deficiency (MSD; MIM\#272200) is one of the rarest lysosomal disorders, with fewer than 50 published cases. ${ }^{1}$ MSD is also referred to as Austin disease, ${ }^{2}$ who first described it as a form of metachromatic leukodystrophy. The clinical phenotype varies in severity and encompasses features of single sulfatase deficiencies: metachromatic leukodystrophy; mucopolysaccharidoses II, IIIA, IIID, IVA, and VI; X-linked ichthyosis; and chondrodysplasia punctata. ${ }^{3}$ Age-dependent presentations of MSD are categorized into the neonatal, ${ }^{4}$ late infantile, and infantile and juvenile forms. ${ }^{5}$

Seventeen sulfatases are encoded in the human genome, eight of which are associated with diseases resulting from single sulfatase deficiencies. ${ }^{6}$ Sulfatases are necessary for nonredundant desulfation of glycosaminoglycans and sulfatides in lysosomes and steroid sulfates in the endoplasmic reticulum. All human sulfatases have a related biochemical function, as evident from sequence comparison, and share a common control of their

From the Departments of Paediatrics (CP, CAR, CC, MN, DR, SS, ANP), Biochemistry (CAR), Children's Health Research Institute (CP, CAR, CC, ANP), Western University, Pathology (DR, CAR) and Medical Imaging (KYT), Department of Ophthalmology (SS), Schulich School of Medicine (CP, CAR, CC, MN, DR, KYT, SS, ANP), Western University, London, Ontario, Canada.

Received January 6, 2014. Final Revisions Submitted April 29, 2014.

Correspondence to: Chitra Prasad, Associate Professor in Paediatrics, Children's Hospital, London Health Sciences Centre, 800 Commissioners Road East, London, Ontario, Canada N6C 2V5. Email: Chitra.Prasad@lhsc.on.ca. 
activity. Several human sulfatases play a role in the normal functioning of the central nervous system. The primary defect in MSD lies in the unique posttranslational activation of newly synthesized sulfatases by the formylglycine-generating enzyme (FGE). ${ }^{7}$ FGE, the protein product of the SUMF1 gene, belongs to a previously identified protein family classified as having "unknown function." SUMF1 is both an essential and a limiting factor for sulfatases. ${ }^{8,9}$ Human FGE forms the bottleneck in the activation of all sulfatases. ${ }^{7,10,11}$ Both residual enzyme activity and protein stability of mutant FGE contribute to the clinical phenotype of MSD. ${ }^{10,12}$ There may be additional factors influencing FGE function acting as disease modifiers.

\section{Case Report}

A 26-month-old boy presented to the Neurometabolic clinic at our institution (Children's Hospital, London Health Sciences Centre) with severe generalized hypotonia. His parents were nonconsanguineous and of Caucasian ethnic background. He was born at 41 weeks' gestation by spontaneous vaginal delivery with a birth weight of $4 \mathrm{~kg}$ (75th-70th centile). At the age of 4 months, impairment in visual fixation and tracking were detected. Poor head control, poor suck, and recurrent episodes of vomiting and pneumonia were also present. He was initially seen in an ophthalmology clinic for his parents' visual concerns. He had clinical features of ocular albinism, namely photophobia, foveal hypoplasia, and iris trans-illumination defects. Visual evoked responses showed chiasmal misrouting. Molecular genetic testing was done in an ophthalmology clinic for pathogenic mutations of ocular albinism and Chediak Higashi syndrome (because his ocular albinism was thought to be complex); this testing did not detect pathogenic mutations. The mother's eye examination also revealed iris trans-illumination, typical in ocular albinism.
However, her fundus was normal. There was no history of seizures or skin rashes in the proband. Developmentally, he was able to roll over supine to prone at 7 months of age. At 15 months, he could commando crawl along the floor with his arms; however, he was unable to crawl using all four limbs. At 22 months, he was able to sit independently and pull-to-stand. He never developed the ability to cruise or walk. Approximately 2 months before his presentation, a decline in his motor skills was noted. At 3 years, he was unable to sit independently. He could no longer pull himself along the floor or pull himself to stand. By parental report, he lost head control and was unable to maintain head posture. At presentation, he had a palmar grasp and by report had lost the skill of a pincer grasp in the use of his hands. He did transfer objects between hands, but could not hold a pencil or scribble. In the domain of speech and language, he was nonverbal. The parents felt that he did make some consonant sounds and possibly responded to his own name being called. In regard to social skills he had a social smile and could laugh. He played peek-a-boo. He brought objects to his mouth for oral exploration. He was able to feed himself with finger foods; however, his parents felt that he was losing this ability and tended to spill food easily. At the age of 3 year and 3 months, he had regressed significantly and was performing at around a less than 6 month age level.

On examination at 3 years, his weight was $13.6 \mathrm{~kg}$ (10th centile), length was $90 \mathrm{~cm}$ (3rd centile), and head circumference was $52 \mathrm{~cm}$ (50th-95th centile). He had relatively coarse facial features with slight hypertelorism, flat nasal bridge, low set posteriorly rotated ears, small mouth, and mild left eye ptosis (Figure 1a; taken at age 1 year).

At 3 years, he was able to fix and follow objects in close proximity. Visual saccades and smooth pursuit movements were barely detectable. Speech and language development was limited to nonspecific vocalizations. He had very fine nystagmus in both (a)

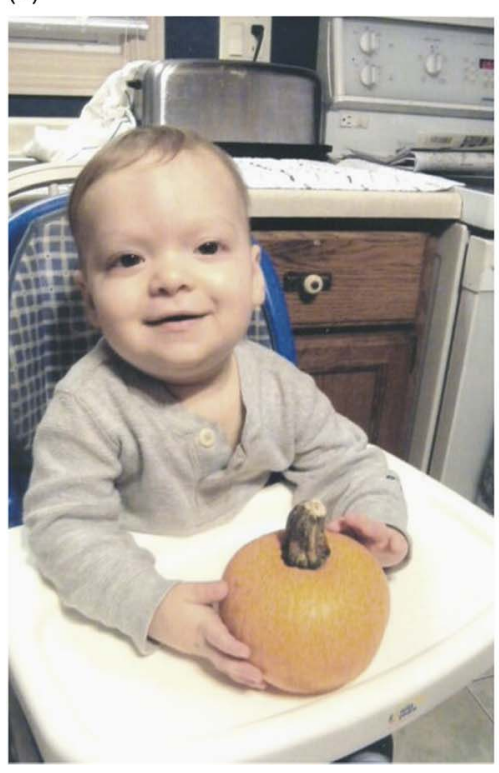

Figure 1: (a) Front view of the patient at age 1 year showing slight coarse facies, mild hypertelorism, and mild left eye ptosis. He is able to sit with minimal support and appears socially appropriate. (b) Front view of the patient at 4 years and 8 months. He is wheelchair bound, is unable to focus, and is nonresponsive to his surroundings. (b)

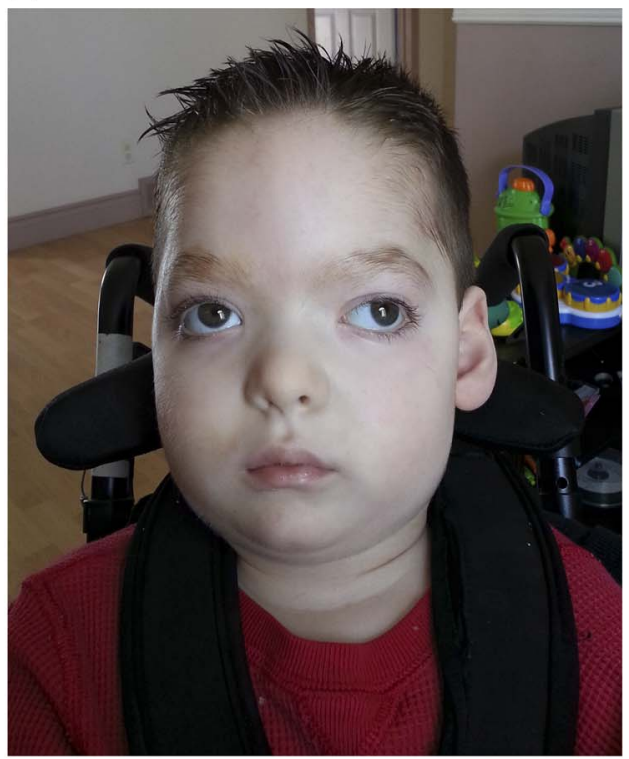


eyes and no corneal clouding. There were no other bony or limb abnormalities, no skin ichthyosis, and no heart involvement. His thumbs were slightly short. Organomegaly was not present. Motor examination disclosed significant head lag, severe generalized hypotonia, and hypoactive to absent deep tendon reflexes. He was unable to sit without support. Fine motor skills were limited to only primitive grasp. Socially, he had poor interactive skills. Motor and sensory nerve conduction velocities were slow and in keeping with a dysmyelinating motor sensory neuropathy on nerve conduction studies (NCS). Currently, the patient has a gastrostomy tube for feeding and has been receiving palliative care since the age of 3 years and 9 months. At present, he is completely nonresponsive, having lost speech and language vocalization and all of his gross motor and fine motor skills (Figure 1b; taken at age 4 years and 8 months). Recently, he was also found to have significant generalized ichthyosis, which required the frequent use of skin-moistening creams and lotions.

\section{ReSUlts}

\section{Biochemical Testing}

Plasma very long chain fatty acids, lactate levels, and transferrin isoelectric focusing were normal. Urine for mucopolysaccharides showed mild elevations at $20.5 \mathrm{mg} / \mathrm{mmol}$ creatinine (reference $3.6-13.4 \mathrm{mg} / \mathrm{mmol}$ creatinine), with heparan sulfate predominating. Further urine analysis confirmed the presence of sulfatides. The activities of other sulfatases were low in fibroblasts: heparan sulfate sulfamidase, $6.5 \mathrm{nmoles} / \mathrm{mg} / \mathrm{protein} /$ 17 hour (reference 25.0-75.0); iduronate-2-sulfate sulfatase, $9 \mathrm{nmol} / \mathrm{mg} / \mathrm{protein} / 4$ hour (reference 31-110); and arylsulfatase A, $3.8 \mathrm{nmoles} / \mathrm{hr} / \mathrm{mg}$ protein (reference 22-50). The activities of other lysosomal enzymes including $\alpha$-glucosidase, $\beta$-galactocerebrosidase, and $\beta$-galactosidase were all normal.

\section{Pathology}

Electron microscopic examination of skin fibroblasts revealed nonspecific pleomorphic lysosomal inclusions in the Schwann cells (Figures 2a and 2b). ${ }^{13}$ The other cytological elements in the biopsy, including fibroblasts, sweat ducts, and vascular endothelial cells and smooth muscle were ultrastructurally unremarkable.

\section{Cranial Imaging and Skeletal Survey}

A skeletal survey showed the presence of ovoid lumbar vertebral bodies suggestive of storage disease. Cranial MRI at the age of 2 years and 11 months demonstrated bilateral symmetrical white matter hyperintensities sparing the subcortical U-fibers on the T2-weighted fluid-attenuated inversion recovery sequence. Cranial MRI was normal at age 11 months. This supports the hypothesis that white matter signal abnormalities are due to dysmyelination induced demyelination (Figures 3a, 3b; Figures 4a, 4b).

\section{Molecular Testing}

Array comparative genomic hybridization and molecular testing for Pelizaeus-Merzbacher disease were negative. He was homozygous for the ARSA pseudodeficiency alleles p.N352S and c. ${ }^{*} 96 \mathrm{~A}>\mathrm{G}$. Two previously described mutations in SUMF1 were identified-c.836 C > T (p.A279V) and c.1045C > T (p.R349W)— confirming the diagnosis of MSD.

\section{DisCUSSION}

In our patient, the presence of ocular albinism was the focus of the initial investigative work-up through an ophthalmology clinic. Chiasmal misrouting was surmised to be due to ocular albinism. Subsequently, his mother was found to have features of ocular albinism indicating an X-linked form of ocular albinism rather than other conditions associated with chiasmal misrouting such as Angelman syndrome. He tested negative to mutations in the OA1, OCA1, OCA2, OCA3, and OCA4 genes. Array comparative genomic hybridization was also carried out as a screening test for a child with hypotonia and developmental delay.

The presence of nystagmus and dysmyelinating motor sensory neuropathy along with central white matter changes on neuroimaging
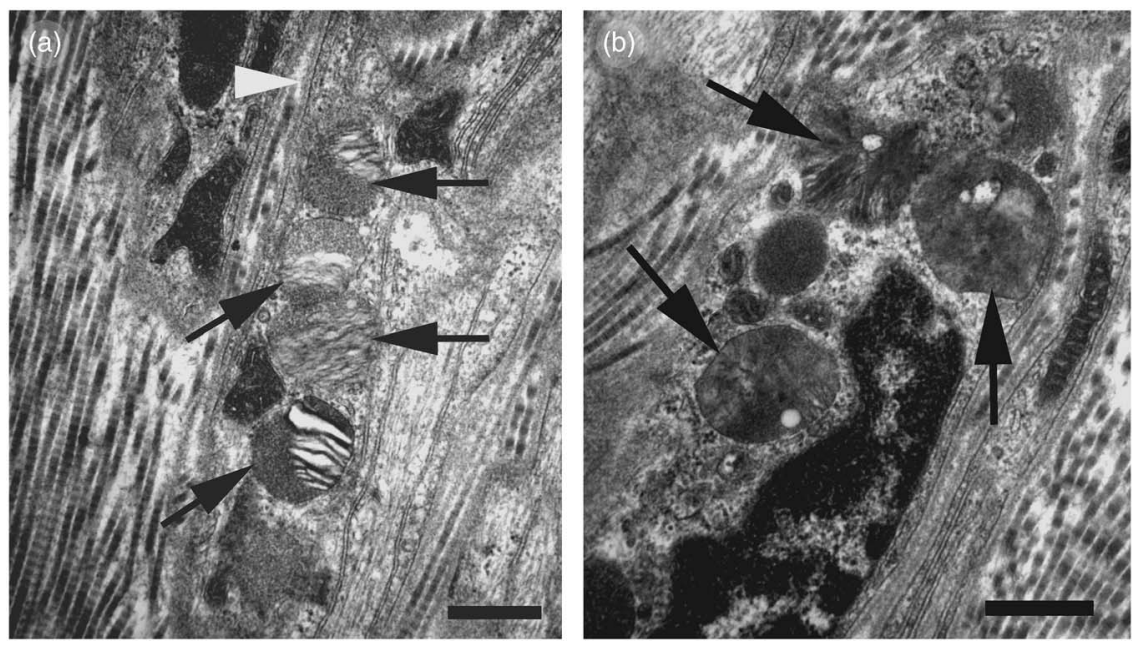

Figure 2: (a) The lysosomes (black arrows) in the Schwann cell (note the basal lamina [white arrowhead]) contain lipid with pleomorphic morphology. In this case, the lipid is characterized by various more or less ill-defined striations, reminiscent of zebra bodies. Scale bar $=500 \mathrm{~nm}$. (b) In this Schwann cell, the lysosomal lipid storage is in the form of uneven flocculent and focally vacuolated material and ill-defined radial arrays (arrows). Scale bar $=500 \mathrm{~nm}$. 

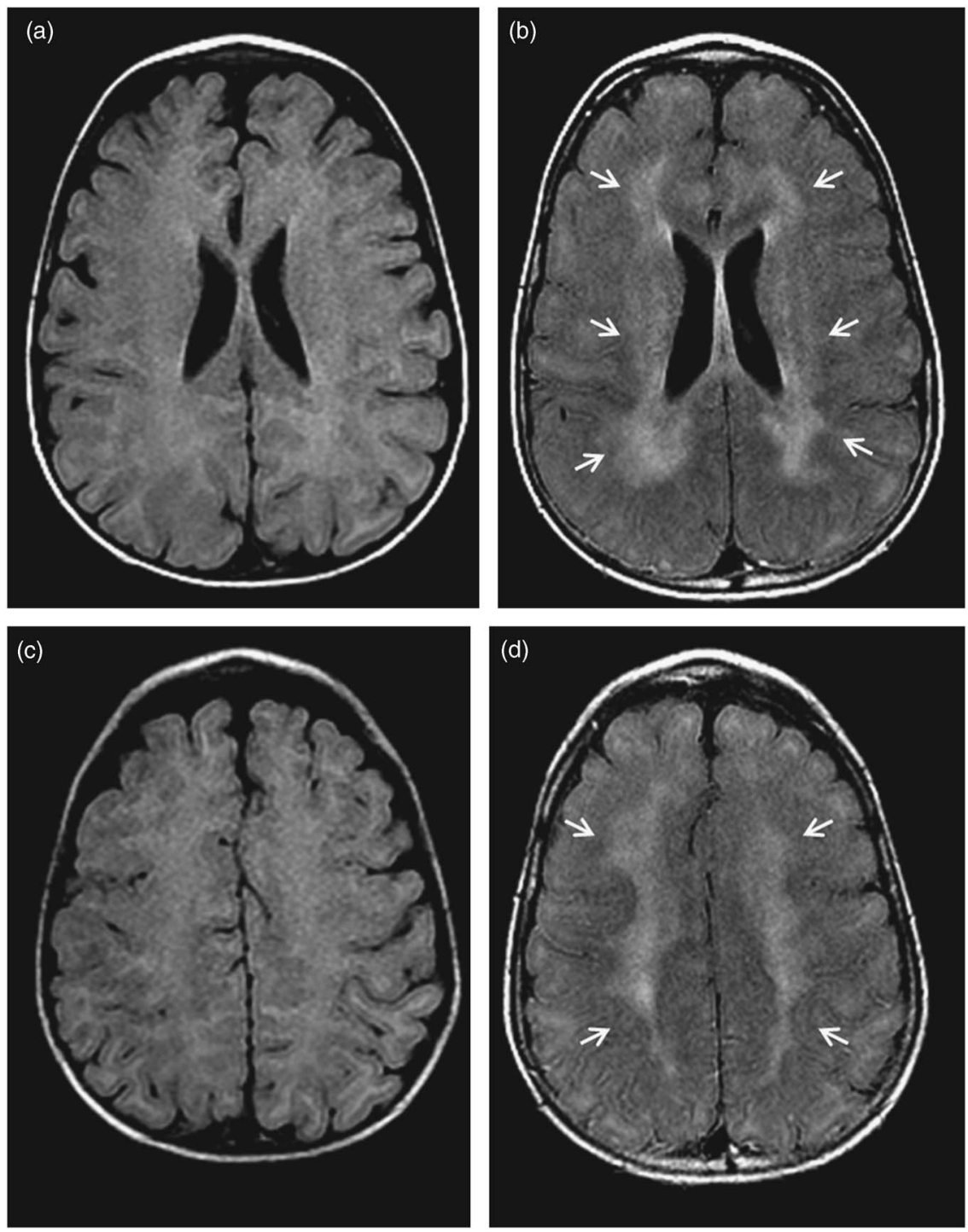

Figure 3: Symmetrical cerebral white matter signal abnormalities (white arrowheads) sparing the subcortical $U$-fibers were demonstrated on the axial T2 fluid-attenuated inversion recovery sequence in the brain MRI performed when the patient was 2 years and 11 months old (Figs $3 b$ and $3 d$ ). They were normal when the patient was 11 months old (Figs $3 a$ and $3 c$ ).

(i.e., abnormal cerebral white matter signal sparing the subcortical fibers) prompted testing for Pelizaeus-Merzbacher disease, which was negative. The presence of significant neurological regression in our patient guided further investigations. Metachromatic leukodystrophy was considered on the basis of the clinical presentation and abnormal white matter signals within the cerebral white matter sparing the $\mathrm{U}$ fibers on cranial MRI. The diagnosis of MLD was supported by the low arylsulfatase A activity and urine sulfatide excretion; however, homozygosity for arylsulfatase pseudodeficiency alleles in the absence of pathological mutations did not support the diagnosis. ${ }^{14}$

As the infant aged, dysmorphic and skeletal features became more prominent. His coarse facies, skeletal survey findings of ovoid lumbar vertebra, and skin biopsy pathology, which demonstrated pleomorphic lysosomal inclusions in Schwann cells, prompted consideration of a mucopolysaccharidosis. Urine mucopolysaccharides excretion was mildly elevated, with heparan sulfate predominating. A diagnosis of MSD was then considered and supported by the low levels of activity of multiple sulfatases in cultured skin fibroblasts. FGE measurement is not available on a clinical basis. Subsequent confirmation of MSD was provided by the identification of the two genetic mutations that result in amino acid substitution (p.A279V and p.R349W).

Eye abnormalities have been previously reported in MSD, including retinal degeneration and unique, peripheral lens opacity. 3,15 Ocular albinism in our case is unrelated to MSD. Similarly pseudodeficiency of arylsulfatase A further confounded the diagnosis of MSD in our case. The phenotype of our patient falls in the severe spectrum as he is now completely nonresponsive and in a neuro-vegetative state at age 4 years and 9 months.

The phenotypic spectrum of MSD is caused by the deficiency of several sulfatases (e.g., neurodegenerative course similar to 
MLD, dysmorphisms and organomegaly as seen in mucopolysaccharidoses, skeletal abnormalities of chondrodysplasia punctata and ichthyosis [X-linked ichthyosis]) and can result in a confusing clinical presentation; the diagnostic process can be challenging and often protracted. ${ }^{14,16}$

The diagnosis of multiple sulfatase deficiency requires a high index of suspicion when there are clinical features of hypotonia, developmental delay and regression, skin findings of icthyosis, and in context of white matter signal abnormalities noted on cranial MRI. Investigations include urine for elevated mucopolysaccharides and sulfatides. Skin ultrastructural pathology for inclusions, NCS, follow-up cranial MRI, and performing a skin biopsy for fibroblast culture is important for assaying the activity of other sulfatases. Additionally NCS can be informative. Finally, molecular studies can confirm the diagnosis. A close collaboration with a biochemical genetics laboratory will help in planning the investigative work-up in a complex clinical scenario as in our case.

Schlotawa et al. ${ }^{10,17}$ analyzed the impact of the p.A279V and p.R349W mutations and determined that both mutations reduced the stability of FGE, with the p.R349W being the more severe. Residual FGE activities in fibroblasts from patients homozygous for the p.A279V and p.R349W mutations were $23 \%$ and $1 \%$ of wild type, respectively. Three patients homozygous for p.R349W had severe late infantile disease and a patient homozygous for p.A279V had a milder clinical course. The patient reported here is a compound heterozygote for p.A279V and p.R349W mutations. Schlotawa et al. ${ }^{10,17}$ also reported that fibroblasts from the patient homozygous for the p.A279V had considerably higher levels of activity of three sulfatases (arylsulfatase C, galactose-6-sulphatase, and arylsulfatase A) than did the patients with p.R349W mutations. The activity of two sulfatases, heparan sulfamidase and iduronyl-2-sulfatase, in cultured fibroblasts from the current patient are intermediate between the homozygous p.A279V and p.R349W genotypes reported by Schlotawa et al. ${ }^{12}$ This is consistent with our patient's clinical phenotype, which is of late infantile severe type.

The prognosis is poor for most forms of MSD; the neonatal presentation is usually fatal within 1 year. ${ }^{4}$ Enzyme replacement therapies have been developed for several lysosomal storage diseases. MSD is a lysosomal storage disease; however, the enzyme that is primarily deficient, FGE, is located in the endoplasmic reticulum of cells, where it acts posttranslationally on nascent lysosomal sulfatases. Potential therapies need to enhance the total residual FGE activity in the endoplasmic reticulum. At present, management remains largely symptomatic and supportive. Genetic counselling is recommended for all families.

\section{AdDENDUM}

Unfortunately, at time of publication the patient is deceased. At time of death he was approximately 4 years and 10 months old.

Electronic database information. URLs used in preparation of this article are:

Locus Link. National Center for Biotechnology Information, National Library of Medicine (Bethesda, MD), 1999. http://www. ncbi.nlm.nih.org/LocusLink

Online Mendelian Inheritance in Man, OMIM (TM). Center for Medical Genetics, Johns Hopkins University (Baltimore, MD) and National Center for Biotechnology Information, National
Library of Medicine (Bethesda, MD), 1999. http://www.ncbi.nlm. nih.gov/omim/

\section{ACKNOWLEDGEMENTS AND FUnding}

Parts of this paper were presented at the 9th Annual WORLD Symposium in Orlando, Florida, February 2013. We are grateful to the family for providing their cooperation and permission for presenting this case report, as well as the biochemical genetics laboratory at London Health Sciences Centre and Drs. Bruce Gordon and Jack Rip for biochemical analyses.

The authors did not receive any financial support for writing this paper.

\section{STATEMENT OF AUTHORShIP}

CP wrote the initial draft and did the revisions of the manuscript. CAR performed the biochemical and molecular analysis for pseudodeficiency allele of Arylsulfatase A; he also helped with revisions of manuscript. CC helped with editing and revision of the manuscript. MN helped with editing and revision of the manuscript. DR provided the pathology slides for publication and helped with revision of the manuscript. KYT provided the cranial imaging slides and helped with revision of the manuscript. SS helped with the ophthalmological findings in this case and with revision of the manuscript. ANP helped with the initial draft, concept, and revisions of the manuscript.

\section{REFERENCES}

1. Hopwood JBA. Multiple sulfatase deficiency and the nature of the sulfatase family. In: Scriver CR, Valle D, Sly WS, editors. The metabolic and molecular bases of inherited Diseases. NewYork: McGraw-Hill; 2001, p. 3725-32.

2. Austin JH. Studies in metachromatic leukodystrophy. XII. Multiple sulfatase deficiency. Arch Neurol. 1973;28:258-64.

3. Blanco-Aguirre ME, Kofman-Alfaro SH, Rivera-Vega MR, et al. Unusual clinical presentation in two cases of multiple sulfatase deficiency. Pediatr Dermatol. 2001;18:388-92.

4. Busche A, Hennermann JB, Burger F, et al. Neonatal manifestation of multiple sulfatase deficiency. Eur J Pediatr. 2009;168:969-73.

5. Eto Y, Gomibuchi I, Umezawa F, Tsuda T. Pathochemistry, pathogenesis and enzyme replacement in multiple-sulfatase deficiency. Enzyme. 1987;38:273-9.

6. Annunziata I, Bouche V, Lombardi A, Settembre C, Ballabio A. Multiple sulfatase deficiency is due to hypomorphic mutations of the SUMF1 gene. Hum Mutat. 2007;28:928.

7. Dierks T, Schmidt B, Borissenko LV, et al. Multiple sulfatase deficiency is caused by mutations in the gene encoding the human C(alpha)formylglycine generating enzyme. Cell. 2003;113:435-44.

8. Fraldi A, Zito E, Annunziata F, et al. Multistep, sequential control of the trafficking and function of the multiple sulfatase deficiency gene product, SUMF1 by PDI, ERGIC-53 and ERp44. Hum Mol Genet. 2008;17:2610-21.

9. Cosma MP, Pepe S, Annunziata I, et al. The multiple sulfatase deficiency gene encodes an essential and limiting factor for the activity of sulfatases. Cell. 2003;113:445-56.

10. Schlotawa L, Ennemann EC, Radhakrishnan K, et al. SUMF1 mutations affecting stability and activity of formylglycine generating enzyme predict clinical outcome in multiple sulfatase deficiency. Eur J Hum Genet. 2011;19:253-61.

11. Dierks T, Dickmanns A, Preusser-Kunze A, et al. Molecular basis for multiple sulfatase deficiency and mechanism for formylglycine generation of the human formylglycine-generating enzyme. Cell. 2005; 121:541-52.

12. Schlotawa L, Radhakrishnan K, Baumgartner M, et al. Rapid degradation of an active formylglycine generating enzyme variant leads to a late infantile severe form of multiple sulfatase deficiency. Eur J Hum Genet. 2013;21:1020-3. 
13. Macaulay RJ, Lowry NJ, Casey RE. Pathologic findings of multiple sulfatase deficiency reflect the pattern of enzyme deficiencies. Pediatr Neurol. 1998;19:372-6.

14. Harbord M, Buncic JR, Chuang SA, Skomorowski MA, Clarke JT. Multiple sulfatase deficiency with early severe retinal degeneration. J Child Neurol. 1991;6:229-35.

15. Santos RP, Hoo JJ. Difficulty in recognizing multiple sulfatase deficiency in an infant. Pediatrics. 2006;117:955-8.
16. Mancini GM, van Diggelen OP, Huijmans JG, Stroink H, de Coo RF. Pitfalls in the diagnosis of multiple sulfatase deficiency. Neuropediatrics. 2001;32:38-40.

17. Schlotawa L, Steinfeld R, von Figura K, Dierks T, Gartner J. Molecular analysis of SUMF1 mutations: stability and residual activity of mutant formylglycine-generating enzyme determine disease severity in multiple sulfatase deficiency. Hum Mutat. 2008;29:205 